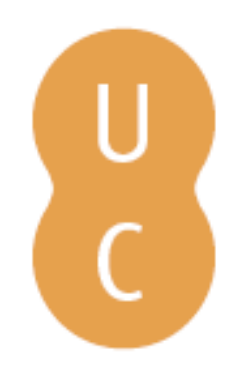

\title{
pommalina
}

\section{A implementação de equipamentos estruturantes como factor de desenvolvimento do sistema urbano}

\author{
Autor(es): $\quad$ Ferreira, Ana Márcia; Rosário, Andreia \\ Publicado por: Imprensa da Universidade de Coimbra \\ URL \\ persistente: URI:http://hdl.handle.net/10316.2/31139 \\ DOI: $\quad$ DOI:http://dx.doi.org/10.14195/978-989-26-0244-8_61 \\ Accessed : $\quad$ 26-Apr-2023 14:35:55
}

A navegação consulta e descarregamento dos títulos inseridos nas Bibliotecas Digitais UC Digitalis, UC Pombalina e UC Impactum, pressupõem a aceitação plena e sem reservas dos Termos e Condições de Uso destas Bibliotecas Digitais, disponíveis em https://digitalis.uc.pt/pt-pt/termos.

Conforme exposto nos referidos Termos e Condições de Uso, o descarregamento de títulos de acesso restrito requer uma licença válida de autorização devendo o utilizador aceder ao(s) documento(s) a partir de um endereço de IP da instituição detentora da supramencionada licença.

Ao utilizador é apenas permitido o descarregamento para uso pessoal, pelo que o emprego do(s) título(s) descarregado(s) para outro fim, designadamente comercial, carece de autorização do respetivo autor ou editor da obra.

Na medida em que todas as obras da UC Digitalis se encontram protegidas pelo Código do Direito de Autor e Direitos Conexos e demais legislação aplicável, toda a cópia, parcial ou total, deste documento, nos casos em que é legalmente admitida, deverá conter ou fazer-se acompanhar por este aviso.






\section{TRUNFOS DE UMA}

\section{EOGRAFIA ACIVA}

\section{DESENVOLVIMENTO LOCAL,}

AMBIENTE,

ORDENAMENTO

E TECNOLOGIA

Norberto Santos

Lúcio Cunha

COORDENAÇÃO 
Ana Márcia Ferreira, Andreia Rosário

IDE - Instituto de Dinâmica do Espaço

Faculdade de Ciências Sociais e Humanas, Universidade Nova de Lisboa

\section{A IMPLEMENTAÇÃO DE EQUIPAMENTOS ESTRUTURANTES COMO FACTOR DE DESENVOLVIMENTO DO SISTEMA URBANO}

\section{INTRODUÇÃO}

O Programa Operacional Temático Valorização do Território (POVT) inclui-se na Agenda Valorizaçáo do Território, uma das três agendas temáticas - onde se inclui também a Agenda para o Potencial Humano e a Agenda para os Factores de Competitividade inseridas no desígnio do QREN - Quadro de Referência Estratégico Nacional para o período de 2007 - 2013. Este Programa Operacional é financiado pelos fundos comunitários do FEDER e do Fundo de Coesão.

No âmbito do Protocolo, entre o Programa Operacional Temático Valorização do Território e o Instituto de Dinâmica do Espaço (IDE), da Universidade Nova de Lisboa, para a Prestação de Serviços de Reforço da Capacidade Institucional para a Análise das candidaturas submetidas ao POVT foram definidos os seguintes objectivos de trabalho:

o Verificação das condiçóes gerais de admissibilidade e aceitabilidade dos beneficiários;

o Verificação das condiçóes gerais de admissibilidade e aceitabilidade das operaçóes;

o Verificação das condiçóes específicas de admissibilidade e aceitabilidade das operaçóes;

o Elaboração de pareceres técnicos incidindo, especialmente sobre a elegibilidade da despesa, o contributo da operação para os resultados do Programa e a análise do mérito da operação, com base na aplicação dos critérios de selecção e metodologia aprovados;

o Elaboração de propostas de Decisão de Financiamento;

o Elaboração do Contrato de Financiamento.

A Equipa técnica do IDE, constituída maioritariamente por geógrafos, foi dividida pelos vários domínios de intervençáo do Programa Operacional ${ }^{1}$, sendo agora abordados

\footnotetext{
${ }^{1}$ Eixo I - Redes e Equipamentos Estruturantes Nacionais de Transportes;

Eixo II - Rede Estruturante de Abastecimento de Água e Saneamento;

Eixo III - Prevenção, Gestão e Monitorização de Riscos Naturais e Tecnológicos;

Eixo IV - Redes e Equipamentos Estruturantes da Região Autónoma dos Açores;

Eixo V - Redes e Equipamentos Estruturantes da Região Autónoma da Madeira;

Eixo VI - Investimentos Estruturantes do Empreendimento de Fins Múltiplos de Alqueva;

Eixo VII - Infra-estruturas para a Conectividade Territorial;

Eixo VIII - Infra-estruturas Nacionais para a Valorização de Resíduos Sólidos Urbanos;

Eixo IX - Desenvolvimento do Sistema Urbano Nacional;

Eixo X - Assistência Técnica.
} 
os procedimentos do trabalho realizado no âmbito do domínio de intervençáo «Equipamentos Estruturantes do Sistema Urbano Nacional», do Eixo Prioritário IX - Desenvolvimento do Sistema Urbano Nacional.

Neste contexto, importa apresentar o conceito de Equipamento Estruturante, o qual permite perceber o objectivo e a importância da abertura de um período para apresentaçáo de candidaturas ao presente domínio.

Segundo o Vocabulário de Termos e Conceitos do Ordenamento do Território, da DGOTDU (2005) os equipamentos de utilização colectiva «são edificaçóes onde se localizam actividades destinadas à prestação de serviços de interesse público imprescindíveis à qualidade de vida das populaçóes. Sáo utilizadores de espaço e devem ser devidamente identificados nos Instrumentos de Gestão Territorial. A sua programação e planeamento aos vários níveis são fundamentais para a vivência das populaçóes e para a qualificação dos espaços urbanos sendo que, alguns deles, de nível superior, são altamente estruturantes do território como é o caso, por exemplo, do ensino superior».

No entanto, existem também outras noçôes que se associam directamente à programação de equipamentos, encontrando-se estas contempladas nos principais documentos de orientação para a apresentação de candidaturas a financiamento comunitário, nomeadamente nos Artigos $2^{\circ}$ e $3^{\circ}$ do Regulamento Específico do domínio dos Equipamentos Estruturantes do Sistema Urbano Nacional. Assim, foram condiçóes essenciais para a aprovação de candidaturas as seguintes especificaçóes do equipamento:

o Equipamentos que prestam um serviço especializado;

o Bem / equipamento raro;

o Área de influência e irradiação alargada;

o Condiçôes de acesso satisfatórias;

o Geração de repercussóes na hierarquia da rede urbana;

o Complementação/qualificação das redes nacionais de equipamentos estruturantes;

o Carácter inovador ou único;

o Contribuição para a atracçáo e competitividade de uma cidade.

Foi, de igual modo, determinado que este eixo, e em particular este domínio, seria destinado a candidaturas de operaçóes que concorressem para «a criação ou requalificação de equipamentos especializados, de elevada raridade ou de grande área de influência, com efeitos estruturantes na diferenciação e competitividade dos principais centros urbanos» ${ }^{2}$, e que tivessem por objectivo o «apoio à construçáo ou requalificaçáo de equipamentos especializados de elevada raridade ou dotados de grande área de influência, que contribuam para a estruturação e desenvolvimento do sistema urbano nacional, para a afirmação e diferenciação dos centros urbanos dos níveis superiors da hierarquia e, no contexto global do país, para o reforço do policentrismo»" ${ }^{3}$. No mesmo Regulamento Específico, estavam ainda claramente descritas as Tipologias das Operaçóes - Artigo $3^{\circ}-$ em que as candidaturas seriam submetidas a concurso, designadamente às três categorias de operações (alíneas a), b) e c):

a) Equipamentos urbanos da iniciativa da Administração Pública Central necessários ao completamento e qualificação das redes nacionais de equipamentos estruturantes;

\footnotetext{
${ }^{2}$ Artigo $3^{\circ}$ do Regulamento Específico - Objectivos

${ }^{3}$ Artigo $2^{\circ}$ do Regulamento Específico - Objectivos
} 
b) Equipamentos urbanos inovadores ou únicos, da iniciativa de entidades de âmbito nacional, que contribuam para o reforço de policentrismo e para a melhoria do potencial de sistema urbano;

c) Equipamentos urbanos que contribuam para a diferenciação e reforço dos factores de atracção e competitividade de uma cidade e para a sua imagem distintiva no contexto nacional.

Ainda no Artigo $3^{\circ}$ era mencionado que os equipamentos a apoiar «devem corresponde a equipamentos de grande relevância para o reforço das funçóes urbanas, nomeadamente nos domínios da saúde, da inovação, do conhecimento, do ensino superior incluindo acção social, da cultura e de suporte à dinamização das actividades económicas. As operaçóes devem, assim, apresentar elevada relevância para o desenvolvimento do sistema urbano nacional».

\section{ENQUADRAMENTO}

No que se refere ao enquadramento nacional e comunitário que estabelece as condições de acesso e as regras gerais de atribuição de financiamento FEDER / Fundo de Coesão, para o domínio dos Equipamentos Estruturantes do Sistema Urbano Nacional, previsto no Eixo Prioritário IX do Programa Operacional Temático Valorização do Território encontramos orientaçóes nos seguintes documentos:

$\checkmark$ Quadro de Referência Estratégico Nacional 2007 - 2013 | Portugal

$\checkmark$ Comissão Ministerial de Coordenação do QREN - Regulamento Geral FEDER e Fundo de Coesão

$\checkmark$ Aviso de Abertura de Candidaturas do POVT datado de 12 de Maio de 2008

$\checkmark$ Regulamento Específico - Equipamentos Estruturantes do Sistema Urbano Nacional

$\checkmark$ Manual de Procedimentos do Programa Operacional Temático Valorização do Território

Quadro de Referência Estratégico Nacional 2007 - 2013 | Portugal

O Quadro de Referência Estratégico Nacional (QREN) assume como grande desígnio estratégico a qualificação dos portugueses, valorizando o conhecimento, a ciência, a tecnologia e a inovação, bem como a promoção de níveis elevados e sustentados de desenvolvimento económico e sociocultural e de qualificação territorial, num quadro de valorização da igualdade de oportunidades e, bem assim, do aumento da eficiência e qualidade das instituiçôes públicas. A prossecução deste grande desígnio estratégico indispensável para assegurar a superação dos mais significativos constrangimentos à consolidaçáo de uma dinâmica sustentada de sucesso no processo de desenvolvimento económico, social e territorial de Portugal, é assegurada pela concretização com o apoio dos Fundos Estruturais e o Fundo de Coesão, por todos os Programas Operacionais, no período 2007-2013, das três Agendas Temáticas.

A Agenda Operacional Temática para a Valorização do Território pretende dotar o país e as suas regióes e sub-regióes de melhores condiçóes de atractividade para o investimento pro- 
dutivo e de condições de vida para as populaçóes e abrange as intervençóes de natureza infra-estrutural e de dotação de equipamentos essenciais à qualificação dos territórios e ao reforço da coesão económica social e territorial. Incide ainda sobre o reforço da conectividade internacional, das acessibilidades e da mobilidade, protecção e valorização do ambiente, política de cidades e redes, infra-estruturas e equipamentos para a coesão territorial e social.

No quadro da Valorização do Território o leque de intervençôes previsto para o próximo ciclo de apoios estruturais comunitários assume uma perspectiva integrada dirigida à concretização dos seguintes objectivos fundamentais:

o Superação dos défices de conectividade internacional e de mobilidade e acessibilidade nacionais, consolidação das redes, infra-estruturas e equipamentos relevantes para a articulação, valorização das actividades económicas e coesão do território;

o Elevação das dotaçôes em redes e infra-estruturas no domínio ambiental;

o Aumento dos níveis de salvaguarda e valorização dos recursos naturais;

o Reforço e prevenção, gestão e monitorização de riscos naturais e tecnológicos.

As operaçóes estratégicas assumidas por Portugal no âmbito do QREN e, em particular, a estrutura organizativa adoptada para os seus Programas Operacionais, associadas ao modelo de governaçáo aprovado, recomendaram a adopção de um esforço acrescido de estabelecimento objectivo e público dos normativos aplicáveis aos fundos estruturais e de coesão para o período 2007-2013. Nesta perspectiva, considerou a Comissão Ministerial de Coordenação (CMC) do QREN que o FEDER e o Fundo de Coesão devem ser objecto de um regulamento geral que regule a sua aplicaçáo em plena coerência com as disposiçóes legais nacionais e comunitárias aplicáveis, que sobre este prevalece, formulado numa perspectiva de salvaguarda do princípio da responsabilidade financeira do Estado Membro pela boa utilização dos fundos.

Aviso de Abertura de Candidaturas ao Programa Operacional Temático Valorização do Território (Datado de 12 de Maio de 2008)

Corresponde ao documento publicado na página online do Programa Operacional que estabelece/define:

$\checkmark$ Objectivos e Tipologias de Operaçóes;

$\checkmark$ Dois períodos temporais distintos para apresentação de candidaturas;

$\checkmark$ Modo e condiçóes de apresentação de candidaturas;

$\checkmark$ Dotação orçamental FEDER afecta ao Aviso (225 Milhões de Euros)

$\checkmark$ Taxa Máxima de Co-Financiamento (70\% do total da despesa elegível)

$\checkmark$ Âmbito Territorial

$\checkmark$ Modo de selecção das candidaturas

$\checkmark$ Apuramento de Mérito, aplicado às candidaturas aceites

Regulamento Específico dos Equipamentos Estruturantes do Sistema Urbano Nacional

Estabelece as condiçóes de acesso e as regras gerais de atribuição de co-financiamento comunitários FEDER, às operaçóes apresentadas no âmbito do domínio de intervenção Equipamentos Estruturantes do Sistema Urbano Nacional. Define ainda as disposiçóes gerais, nomeadamente: 
$\checkmark$ Objectivos de Intervenção;

$\checkmark$ Disposiçóes Gerais - também referenciadas no Aviso de Abertura

$\checkmark$ Condiçóes de Elegibilidade das operações

$\checkmark$ Apoios

$\checkmark$ Processo de Atribuição de Co-financiamento

$\checkmark$ Financiamento

$\checkmark$ Acompanhamento e Controlo

$\checkmark$ Disposições Finais

Em resumo, destacamos agora algumas das condiçóes essenciais para a admissibilidade e aceitabilidade das candidaturas no que se refere ao beneficiário e às operaçóes:

1. Condiçóes dos Beneficiários (Artigo 6º):

o Satisfazer as condiçóes gerais estabelecidas no artigo $10^{\circ}$ do Regulamento Geral FEDER e Fundo de Coesão.

o Condições Específicas dos Beneficiários (Artigo 60):

o O objectivo, competências e a natureza das suas actividades devem ser coerentes com os objectivos do domínio de intervenção a que respeita a operação a candidatar;

o Devem comprometer-se a assegurar o cumprimento das disposiçóes legais regulamentares e contratuais associadas ao co-financiamento do FEDER.

2. Condiçôes das Operaçôes (Artigo 70):

o As operaçóes devem estar previstas no artigo $3^{\circ}$ e satisfazer as condiçóes gerais estabelecidas no artigo $11^{\circ}$ do Regulamento Geral do FEDER e Fundo de Coesáo.

o Demonstrar o enquadramento nos objectivos e nas tipologias das operaçóes previstas;

o Enquadrar-se nos objectivos, orientaçóes e prioridades definidas no PNPOT, no PROT e em planos sectoriais e de ordenamento do território;

o Serem apresentadas nos termos, condiçóes e prazos definidos pela Autoridade de Gestão; datura;

o Cumprir todos os requisitos administrativos formais relativos ao processo de candi-

o No caso das operaçóes a que se refere a alínea b) do artigo $3^{\circ}$, demonstrar o carácter inovador ou único do equipamento em causa;

o Demonstrar a viabilidade económico-financeira do equipamento, em particular a capacidade de suportar os custos em exploração;

Manual de Procedimentos do Programa Operacional Temático Valorização do Território

É o documento que estabelece um conjunto de regras e procedimentos a observar pelos beneficiários do programa/domínios de intervenção, desde a instrução das candidaturas, pautando a articulação entre estes e a Autoridade de Gestão. É essencialmente, um documento normativo directamente subordinado aos Regulamentos Comunitários, ao Regulamento Geral FEDER/Fundo de Coesão e aos Regulamentos Específicos do POVT, bem como à legislação nacional e comunitária aplicável. 


\section{CONSIDERAÇÓES FINAIS}

A análise das candidaturas submetidas ao domínio dos «Equipamentos Estruturantes do Sistema Urbano Nacional» do POVT revelou-se uma tarefa que se coaduna totalmente com os objectivos curriculares da formação em Geografia e Planeamento Regional. Tendo em conta que os objectivos estratégicos do QREN são essenciais para a configuração do modelo territorial proposto no PNPOT e nos PROTS, documentos estratégicos essenciais para os Geógrafos já que definem o desenvolvimento sustentado a atingir, no país, nas diversas áreas, considerou-se como uma mais-valia o entendimento do conceito e a importância do planeamento e do ordenamento, bem como a capacidade de análise e interpretação do território e das necessidades da sociedade actual, nomeadamente nas vertentes social, económica, cultural e ambiental dos territórios.

O facto de a Equipa Técnica incorporar técnicos Geógrafos, revelou-se de maior importância pela interpretação mais densa e multifacetada do território o que possibilita a identificação de problemas e a apresentação de soluçôes para a minimização dos mesmos.

\section{REFERÊNCIAS BIBLIOGRÁFICAS}

Comissão Ministerial de Coordenação do QREN, Instituto Financeiro para o Desenvolvimento Regional, IP (IFDR), Outubro de 2008, Regulamento Geral FEDER e Fundo de Coesão, Portugal.

DGOTDU, 2002, Normas para a Programação e Caracterização de Equipamentos Colectivos, Lisboa.

DGOTDU, 2005, Vocabulário de Termos e Conceitos do Ordenamento do Território, Lisboa.

Observatório do QCA III, Ministério do Ambiente, do Ordenamento do Território e do Desenvolvimento Rural, Setembro de 2007, Quadro de Referência Estratégico Nacional - Portugal 2007 - 2013, Portugal.

Programa Operacional Temático Valorização do Território, Setembro de 2007, Proposta de Programa Operacional Temático Valorização do Território 2007-2013, Portugal, pág. 93.

Programa Operacional Temático Valorização do Território, Junho de 2008, Manual de Procedimentos do Programa Operacional Temático Valorização do Território, Portugal.

Programa Operacional Temático Valorização do Território, 12 de Maio de 2008 (actualizado em 14 de Julho de 2008), Aviso de Abertura de Candidaturas, Programa Operacional Temático Valorização do Território, Eixos Prioritário IX - Desenvolvimento do Sistema Urbano Nacional, Equipamentos Estruturantes do Sistema Urbano Nacional, Lisboa.

Programa Operacional Temático Valorização do Território, 17 de Março de 2008, PO Temático Valorização do Território - Eixo IX, Regulamento Específico - Equipamentos Estruturantes do Sistema Urbano Nacional, Lisboa. 